\title{
PARÂMETROS DE COMPLIANCE POR MEIO DA METODOLOGIA DE ANÁLISE DE RISCO PARA A MITIGAÇÃO DA RESPONSABILIDADE OBJETIVA DIANTE DA LEI ANTICORRUPÇÃO (12.846/2013) EM FACE DE NEGÓCIOS PÚBLICOS
}

\section{COMPLIANCE PARAMETERS THROUGH RISK ANALYSIS METHODOLOGY FOR STRICT LIABILITY MITIGATION ACCORDING TO THE LAW ANTI- CORRUPTION (12.846 / 2013) REGARDING PUBLIC BUSINESS}

\author{
${ }^{1}$ Beatriz Miranda Batisti \\ ${ }^{2}$ Marlene Kempfer
}

\section{RESUMO}

A Lei 12.846/2013, tem por escopo combater a corrupção e possibilitar que as empresas possam ser agentes ativos neste intento. $\mathrm{O}$ aspecto repressivo da legislação em comento pode ser mitigado caso a empresa adote estratégias de prevenção por meio de programas de compliance. A efetividade preventiva desta Lei dependerá, contudo, das análises de aspectos jurídicos e gerenciais, para apontar caminhos objetivos diante dos riscos de corrupção. A adoção de parâmetros objetivos para o gerenciamento dos riscos anticorrupção, permite construir um programa de integridade que traz para foco as ações éticas necessárias às empresas que pretendem negociar com a administração pública.

Palavras-chave: Lei anticorrupção, Compliance, Análise de risco

\begin{abstract}
The Law 12,846 / 2013 has the scope to fight it and enable companies to become active agents in this intent. The repressive aspect of the legislation can be mitigated if the company adopts strategies of prevention through compliance programs. The preventive effectiveness of this law will depend on the analysis of legal aspects and business management topics. The risk analysis methodology and the adoption of objective parameters for the management of anti-corruption risks, allows companies to build an integrity program that puts in focus the ethical actions necessary for companies willing to negotiate with the government.
\end{abstract}

Keywords: Anti-corruption law, Compliance, Risk analysis

\footnotetext{
${ }^{1}$ Mestranda em Direito Negocial pela Universidade Estadual de Londrina, UEL - Paraná, PR. (Brasil). Advogada. E-mail: biabatisti@hotmail.com.

${ }^{2}$ Doutora em Direito do Estado pela Pontifícia Universidade Católica de São Paulo, PUC/SP, São Paulo, SP. (Brasil). Professorar da Pontifícia Universidade Católica do Paraná - Campus Londrina, Paraná, PR. (Brasil). Email: mkempferb@gmail.com.
} 


\section{INTRODUÇÃO}

Para dar cumprimento às competências constitucionais do Estado brasileiro de 1988, o Executivo, no desempenho de sua função administrativa, poderá realizar negócios jurídicos com empresas públicas ou privadas. Embora seja desejável que os gestores públicos e privados atuem por meio de codutas lícitas, atualmente, inúmeras condenações em nível administrativo e judicial apontaram para uma realidade de antijuridicidades (infrações e crimes) e que justificou a aprovação da Lei 12.846/13, denominada Lei Anticorrupção.

Esta pesquisa, de natureza bibliográfica, está voltada para destacar os aspectos da responsabilização objetiva das empresas por infrações cometidas em face da Administração pública diante da realização de negócios públicos e a possibilidade de considerar Programas de Integridade e controles internos (compliance), por ocasião da aplicação da sanção legal.

Ao interpretar o texto legal em análise (Art. $7^{\circ}, \mathrm{VIII}$ ), pode-se afirmar que quando a empresa adotar condutas internas que permitam avaliar "mecanismos e procedimentos internos de integridade, auditoria e incentivo à denúncia de irregularidades e a aplicação efetiva de códigos de ética e de conduta no âmbito da pessoa jurídica", poderá haver redução da sanção.

Esta norma pode ser considerada um estímulo para que as empresas implementem ou aperfeiçoem as práticas referidas, uma vez que condutas de corrupção podem ser evitadas ou minoradas. Assim, por meio de controles internos adequando as práticas empresariais conforme a ética jurídica ganha a sociedade e aumentam as possibilidades de manter a empresa na atividade econômica. Neste sentido a importância dos estudos reunidos na Ciência da Administração ao tratar da análise de risco, da gestão de empresas por valores, pois permitem apurar resultados práticos preventivos junto às organizações diante de negócios jurídicos realizados com a Administração pública.

Embora a lei seja bastante ampla quanto aos seus destinatários, neste artigo tratar-seá apenas dos negócios jurídicos que envolvam empresas brasileiras.

Nos termos do artigo 5ำ, a Lei prevê que:

\footnotetext{
“Constituem atos lesivos à administração pública, nacional ou estrangeira, todos aqueles praticados pelas pessoas jurídicas, que atentem contra o patrimônio público nacional ou estrangeiro, contra princípios da administração pública ou contra os compromissos internacionais assumidos pelo Brasil." (BRASIL, Lei 12.846/13)
} 
A Parâmetros de Compliance por meio da Metodologia de Análise de Risco para a Mitigação da Responsabilidade Objetiva Diante da Lei Anticorrupção (12.846/2013) em Face de Negócios Públicos

Desta forma, prometer, oferecer ou dar vantagem indevida a agente público ou pessoa a ele relacionada, usar de interposta pessoa física ou jurídica para financiar a prática de atos ilícitos, frustrar ou fraudar, mediante ajuste o caráter competitivo de procedimento licitatório público, manipular o equilíbrio econômico-financeiro dos contratos celebrados com a administração pública, são exemplos de condutas tipificadas pela Lei 12.846/13 no que diz respeito aos negócios jurídicos celebrados por empresas com a administração pública.

Atos lesivos à administração pública nacional e estrangeira são na realidade condutas que afetam, prejudicialmente, interesses públicos. Entende-se que se referem a disfunções por meio de condutas qualificadas como infração ou crime, desrespeitando princípios constitucionais que devem reger os negócios jurídicos, em especial, o princípio da supremacia do interesse público.

A responsabilização objetiva das empresas pelas infrações descritas no artigo $5^{\circ}$ o aspecto mais inovador e controverso da Lei 12.846/13. Isto porque, a responsabilidade objetiva independe de dolo ou culpa.

De acordo com Carvalhosa (2015, p. 37) "julga-se pelo dano que a conduta corruptiva ativa ou omissiva da pessoa jurídica produziu ao bem jurídico, ou seja, ao Estado”. Assim, na Lei Anticorrupção, a causalidade decorrente do dolo é superada, e o nexo causal se dá a partir da relação de conduta x benefício procurado ou obtido pela pessoa jurídica.

Aplicam-se à administração pública estrangeira os mesmos princípios e proteção dispensada à nacional, em relações jurídicas tuteladas pelo ordenamento jurídico nacional ou em decorrência de Convenções ou Tratados internacionais.

É importante destacar que os atos que atentam contra o patrimônio público nacional ou estrangeiro, contra os princípios da administração pública ou contra os compromissos internacionais assumidos pelo Brasil são, no ordenamento jurídico brasileiro, tipificadas e sancionadas, com base no bem jurídico violado, em quatro grandes esferas: penal, civil, administrativa e política.

Uma mesma conduta pode assim, violar objetos jurídicos distintos e ser sancionada também de forma distinta, sem que corresponda a um bis in idem, nas esferas Penal, Administrativa, Civil e Constitucional. A diferença entre elas será qualitativa. A responsabilidade civil, adotando as definições da Lei 8.112/ decorre de ato omissivo ou comissivo, doloso ou culposo, que resulte em prejuízo ao erário ou a terceiros. Já a responsabilidade penal abrange os crimes e contravenções imputadas aos envolvidos, nessa qualidade. A 
responsabilidade civil-administrativa resulta de ato omissivo ou comissivo praticado no desempenho do cargo ou função.

A Lei Anticorrupção dispõe acerca da responsabilidade objetiva das pessoas jurídicas na esfera administrativa e civil. A opção do legislador pela esfera administrativa tem diversos fundamentos. Carvalhosa (2015, p.37) destaca que "a responsabilização objetiva encontra no processo penal uma dificuldade, qual seja a falta de um dos elementos do delito- o dolo- como vontade livre e consciente de obter benefício que se sabe ilícito". Sendo as infrações cometidas em face da Administração Pública, parece razoável que o regime disciplinar e sancionatório possa também ocorrer em âmbito administrativo.

\section{COMPLIANCE E A FORMAÇÃO DE UMA CULTURA ORGANIZACIONAL}

Se por um lado a Lei 12.846/13 descartou elementos importantes como subjetividade e o dolo nos ilícitos tipificados ao adotar a responsabilidade objetiva na esfera administrativa, por outro, deu a oportunidade para as empresas desenvolverem programas preventivos podendo mitigar significativamente a controversa responsabilidade objetiva.

Não há dúvidas que as sanções são essenciais e irrenunciáveis para o Direito e o exercício da justiça. Entretanto, deve-se levar em consideração o direito sancionador por si só têm pouca capacidade de reparação, ainda que se reconheça certo efeito preventivo.

Por tal razão, no âmbito do cumprimento da lei pelas empresas e corporações, "a função de prevenção mediante um sistema de obrigatório de controle jurídico preventivo dos riscos de responsabilidade normativa (compliance) adquire uma importância similar a das auditorias contábeis no que concerne ao capital social.” (BAGIALUPO, 2011, p. 17). Ou seja, mais que um dever moral empresarial, os programas de integridade e políticas de compliance são essenciais à rotina empresarial.

Instituiu a Lei 12.846/13 em seu artigo sétimo, inciso VIII que “a existência de mecanismos e procedimentos internos de integridade, auditoria e incentivo à denúncia de irregularidades e a aplicação efetiva de códigos de ética e de conduta no âmbito da pessoa jurídica," serão levados em consideração na aplicação das sanções, podendo nos termos do decreto regulamentador reduzir o valor da multa aplicada pela autoridade administrativa. ${ }^{1}$

Neste trabalho serão apresentados critérios que têm o condão de servir de parâmetro para desenvolver e identificar um programa de compliance, e consequentemente, com 
A Parâmetros de Compliance por meio da Metodologia de Análise de Risco para a Mitigação da Responsabilidade Objetiva Diante da Lei Anticorrupção (12.846/2013) em Face de Negócios Públicos

potencial para diminuir até o limite máximo a sanção administrativa (multa), estabelecida por lei.

A lei enumera ainda outras atenuantes da responsabilidade objetiva, destacando a gravidade da infração; a vantagem auferida ou pretendida pelo infrator; a consumação ou não da infração; o grau de lesão ou perigo de lesão, o efeito negativo produzido pela infração; a situação econômica do infrator; a cooperação da pessoa jurídica para a apuração das infrações; a existência de mecanismos e procedimentos internos de integridade, auditoria e incentivo à denúncia de irregularidades e a aplicação efetiva de códigos de ética e de conduta no âmbito da pessoa jurídica; o valor dos contratos mantidos pela pessoa jurídica com o órgão ou entidade pública lesados.

Dar-se-á, entretanto, maior enfoque na questão dos programas de integridade, pois estes tem papel decisivo não apenas na redução da sanção e na mitigação da responsabilidade objetiva, como também na criação de uma cultura organizacional de prevenção e fortalecimento de uma nova mentalidade no jeito de fazer e conduzir negócios no Brasil.

Assim sendo, a discussão sobre a ética empresarial faz-se imperiosa. A ética, por muito tempo esteve restrita ao espectro individual, entretanto, diante do aperfeiçoamento das instituições, a responsabilidade pelo bem comum teve de ser alargada contemplando os demais agentes que compõe a sociedade. Diante deste novo contexto o protagonismo das empresas passa a ser expressivo. Contudo Domingo García-Marzá (2004, p. 32), adverte:

1 Art. 18. Do resultado da soma dos fatores do art. 17 serão subtraídos os valores correspondentes aos seguintes percentuais do faturamento bruto da pessoa jurídica do último exercício anterior ao da instauração do PAR, excluídos os tributos:

I - um por cento no caso de não consumação da infração;

II - um e meio por cento no caso de comprovação de ressarcimento pela pessoa jurídica dos danos a que tenha dado causa;

III - um por cento a um e meio por cento para o grau de colaboração da pessoa jurídica com a investigação ou a apuração do ato lesivo, independentemente do acordo de leniência;

IV - dois por cento no caso de comunicação espontânea pela pessoa jurídica antes da instauração do PAR acerca da ocorrência do ato lesivo; e

$\mathrm{V}$ - um por cento a quatro por cento para comprovação de a pessoa jurídica possuir e aplicar um programa de integridade, conforme os parâmetros estabelecidos no Capítulo IV.

Art. 19. Na ausência de todos os fatores previstos nos art. 17 e art. 18 ou de resultado das operações de soma e subtração ser igual ou menor a zero, o valor da multa corresponderá, conforme o caso, a:

I - um décimo por cento do faturamento bruto do último exercício anterior ao da instauração do PAR, excluídos os tributos; ou

II - R\$ 6.000,00 (seis mil reais), na hipótese do art. 22. 
“isto não significa que a empresa deva ocupar-se dos direitos sociais e conômicos, nem que seja obrigada a fazer-se responsável por aquilo que o Estado tem dificuldades para garantir. Isso não seria possível, nem é desejável. Todavia, deseja-se simplesmente salientar que a empresa deve se incorporar a essa assunção de responsabilidades, na medida correspondente a seu poder e a suas capacidades (GARCÍA-MARZA, 2004, p.32)".

Não há como discutir a eficácia de programas de compliance ou integridade, sem trazer a baila uma discussão axiológica e sem que se aprofunde a questão da cultura organizacional, que sintetiza os valores eleitos pelas organizações de maneira a conduzir e orientar as diversas práticas cotidianas, validando ou refutando aspectos comportamentais e sociais dentro das empresas.

Simon L. Dolan e Salvador García, em sua obra, Gestão por Valores, propõem uma ferramenta de gestão em que os valores passam a ser uma alavanca para a cultura organizacional, de tal sorte que harmonizem as crenças de proprietários e colaboradores no sentido de criar uma vantagem competitiva por meio dos valores eleitos como estratégicos para cada companhia.

A construção de valores chave tem o condão de reformular as relações pessoais, implementar o sentido de responsabilidade implícito nos objetivos organizacionais a par da estratégia em desenvolvimento na empresa, além de apostar e conferir responsabilidade de atuação também aos serviços periféricos

A gestão por valores (GPV) encontra-se alicerçada em três pilares fundamentais:

(i) Os valores econômicos-pragmáticos, necessários para manter e unir vários sistemas organizacionais. Incluem valores relativos à eficácia, padrões de desempenho e disciplina. Estes valores orientam atividades como planejamento, garantia de qualidade e contabilidade.

(ii) Os valores ético-sociais que orientam a forma como as pessoas se comportam em grupo. Emergem de pressupostos acerca de como as pessoas devem agir em público, no trabalho e nas relações. Associam-se a valores sociais como honestidade, congruência, respeito, lealdade. Os valores ético-sociais irão influenciar o comportamento adequado da vivência dos valores pessoais econômico-pragmáticos e dos valores contemplados na dimensão "emocionaldesenvolvimento."

(iii) Os valores "emocionais-desenvolvimento" são essenciais para criação de novas oportunidades de ação. Relacionam-se com a confiança, liberdade e felicidade. (DOLAN-GARCÍA, 2006, p 24). 
A Parâmetros de Compliance por meio da Metodologia de Análise de Risco para a Mitigação da Responsabilidade Objetiva Diante da Lei Anticorrupção (12.846/2013) em Face de Negócios Públicos

A discrepância que emerge entre os valores formalmente declarados e os valores em ação gera falta de compromisso, confusão e absenteísmo psicológico. (DOLAN-GARCÍA, 2006, pg. 17).

Tal conflito é um fator crítico para a eficácia dos mecanismos de compliance. A mera declaração de treinamento realizado ou criação de um Código de Ética não teria o condão de por si só assegurar a efetividade de um programa de integridade, caso este esteja dissociado dos valores concretos praticados no cotidiano empresarial. Quando uma sociedade não possui opções de valor claramente formuladas, diz-se que é anômica (Allport, 1924 apud Dolan- García). Atualmente, a anomia organizacional é capaz de explicar a falta de vitalidade, coerência e moral coletivas, e da vontade de um esforço que pode ser observado em muitas empresas.

Assim para avaliar a eficácia dos mecanismos de compliance e a implementação de uma cultura organizacional em que o combate a corrupção, a honestidade e a transparência sejam valores que orientem os objetivos estratégicos da companhia, e concretizem o aspecto preventivo da Lei Anticorrupção, estes valores devem ser efetivamente vivenciados desde a alta administração até os mais baixos níveis hierárquicos.

Para que se possa adotar uma Gestão Por Valores (GPV), conceitos importantes como: crenças, normas e atitudes, extraídos da psicologia social passam a ser determinantes na formação de uma cultura anticorrupção dentro do ambiente corporativo.

Se os valores, no contexto da GPV são compreendidos como "escolhas estratégicas acerca do que é necessário para a concretização de objetivos" (DOLAN-GARCÍA, p. 35), é necessário ter em mente que as crenças, normas e atitudes são elementos que compõe a formações dos valores e consequentemente da cultura.

Antes de dissecar tais elementos, é conveniente que se exponha o conceito de cultura organizacional consagrado por Edgar Schein como:

\footnotetext{
"modelo de pressupostos básicos que um grupo assimilou na medida em que resolveu os seus problemas de adaptação externa e integração interna e que, por ter sido suficientemente eficaz, foi considerado válido e repassado aos demais novos membros como a maneira correta de perceber, pensar, sentir em relação a estes problemas (SCHEIN,2009, p.16)"
}

Assim, é possível afirmar que a cultura é "universal e influencia todos os aspectos de como uma organização lida com sua tarefa principal, seus vários ambientes e suas operações 
internas.” (SCHEIN, 2009, p.14). Logo, a cultura organizacional atua de maneira a validar ou refutar os comportamentos que estão alinhados ou em dissonância daquilo que foi assimilado pelo corpo social.

Por tratar do resultado de aprendizagem acumulada de um grupo no ambiente corporativo, podendo ser vista como a "personalidade" da empresa - a cultura organizacional exerce forte impacto no modo como a questão da integridade é percebida e gerenciada dentro do ambiente empresarial.

A cultura, enquanto fenômeno social não é inteiramente tangível. Divide-se em níveis ou camadas. Os artefatos compõem a camada mais superficial, a parte concreta e visível da cultura organizacional. Materializa-se nos símbolos, vestes e layouts adotados por uma empresa. Os valores, por sua vez, são abstratos e estão inseridos em um nível um pouco mais profundo, pois dependem de validação social e influenciam e orientam os comportamentos que serão adotados e legitimados. Por fim, os pressupostos básicos, que são a camada nuclear, podem ser conceituados nas palavras de Schein por:

\footnotetext{
"Pressupostos que determinam como os membros de um grupo percebem, pensam e sentem. Na medida em que certos valores compartilhados pelo grupo levam a determinados comportamentos e estes se mostram adequados para solucionar problemas, o valor é gradualmente transformado em um pressuposto inconsciente."
} (SCHEIN, 2009, p. 38)

As crenças são importantes para a compreensão da cultura, pois precedem a formulação dos valores. São "estruturas de pensamento desenvolvidas e profundamente enraizadas ao longo dos anos, através da aprendizagem e experiência que servem para explicar e dar sentido à realidade.” (Dolan-García, 2006, p. 36)

No campo da cultura organizacional, as normas são regras de conduta adotadas por consenso e validadas pelo corpo social. Daí a importância de se ter em mente, que as sanções administrativas, especialmente as de cunho pecuniário como a multa, são suficientes para garantir a eficácia da Lei no aspecto jurídico punitivo, mas não necessariamente no aspecto preventivo.

Para que a finalidade preventiva se concretize é necessário a criação de uma cultura que não tolere nem transija práticas abrangidas no conceito de corrupção. É preciso que a corrupção seja vista efetivamente como um desvalor dentro da empresa, como um 
comportamento vexatório (e não como um "mal necessário" ou um "caminho mais efetivo" para alcançar os fins almejados".)

Para tanto há que se trabalhar para que a norma seja internalizada e legitimada como um aspecto do próprio valor da organização, validada de maneira consensual por todos os integrantes, de tal sorte que aqueles que não possuam tais valores sejam organicamente expulsos pelo corpo social.

Toda mudança cultural é um processo lento e psicologicamente doloroso, uma vez que gera ansiedade e enfrenta resistência, pois meche em estruturas profundas como os valores. Assim, a punição de empresas corruptas e as pressões sociais que emergem diante do desmantelamento de algum escândalo, fortalecem a percepção de que urge repensar os pressupostos básicos, propulsionando mudanças internas.

SCHEIN (2011, p. 30) aponta que as chaves para uma mudança cultural bem sucedida são: “(1) o gerenciamento do grande volume de ansiedade que acompanha qualquer reaprendizagem neste nível e (2) a avaliação de se o potencial genético para a nova aprendizagem esta presente". No que tange ao potencial genético para a nova aprendizagem, é preciso ter em mente que caso se enfrente resistências profundas diante das mudanças, de maneira que as mesmas não sejam incorporadas e provoquem um movimento de contracultura, impedindo a concretização nos novos valores que se pretende adotar, a empresa deverá passar por uma forte reestruturação de maneira a identificar e eliminar da organização os indivíduos incapazes de assimilar as mudanças e novos paradigmas.

\section{ANÁLISE DE RISCOS E CRIAÇÃO DE UM PROGRAMA DE COMPLIANCE}

Uma premissa clássica da Administração ensina que aquilo que não pode ser mensurado, não pode ser gerido. Ora, para avaliar a eficácia de um programa de integridade para fins de redução das sanções administrativas e judiciais, e assegurar que as ferramentas de compliance não fiquem restritas ao campo meramente documental, descoladas de qualquer eficácia social dentro da organização, a adoção de parâmetros objetivos é fundamental.

A criação de um programa robusto e eficiente passa necessariamente pela análise dos riscos envolvidos na atividade a ser desenvolvida pela empresa. A ISO 31.000 que versa sobre a gestão de riscos, define como sendo risco o "efeito das incertezas em um objetivo." (IS0 31000, 2009). Ao levar em conta a análise de risco para a adoção de parâmetros de 
compliance, estabelece-se quais são os possíveis fatores que ameaçam o objetivo de ter uma empresa livre de corrupção, e maneiras de mitigar e evitar que as condutas indesejadas concretizem-se.

O documento elaborado pela controladoria geral da união, de caráter orientativo, denominado: "Diretrizes para as Empresas Privadas", define Programa de Integridade nos seguintes termos: "é um programa de compliance específico para prevenção, detecção e remediação dos atos lesivos previstos na lei 12.846/2013, que tem como foco, além da ocorrência de suborno, também fraudes nos processos de licitações e execução de contratos com o setor público”. (Controladoria Geral da União, 2015).

Nos termos do artigo 41 do Decreto 8.420/2015 programa de integridade consiste, no âmbito de uma pessoa jurídica, no conjunto de mecanismos e procedimentos internos de integridade, auditoria e incentivo à denúncia de irregularidades e na aplicação efetiva de códigos de ética e de conduta, políticas e diretrizes com objetivo de detectar e sanar desvios, fraudes, irregularidades e atos ilícitos praticados contra a administração pública, nacional ou estrangeira.

Como importante medida do Pacto Global da ONU, o combate à corrupção ganha contornos expressivos, porém a despeito dos esforços legislativos como a Lei 12.846/13 e o Decreto 8.420/15 que a regulamentou, o aparato normativo elucida apenas o que se entende por Programa de Integridade, mas não apresenta "como" este deve ser formatado para que alcance a efetividade preventiva e transformadora esperada pela Lei.

O modelo de gestão do Pacto Global demanda um comprometimento em concretizar os objetivos e integrar os princípios assumidos de maneira transparente. A avaliação dos riscos, oportunidades e impactos envolvidos nas áreas em que os compromissos foram assumidos, como no caso do combate à corrupção, deverá ser feita por meio da definição de metas, estratégias e políticas, de maneira que sejam implementadas, medidas, geridas e posteriormente comunicadas para que se viabilize a melhoria contínua dos processos.

A prevenção da corrupção passa necessariamente pela compreensão dos riscos envolvidos em determinado setor e determinada atividade. Os elementos que tornam uma empresa mais ou menos vulnerável ou suscetível às infrações descritas no artigo quinto da Lei Anticorrupção variam a depender de fatores de ordem geográfica, cultural, da natureza da atividade principal da empresa, nível e frequência de contato com órgãos e autoridades públicas, existência de controles internos, testes de auditoria e checklists, 
A Parâmetros de Compliance por meio da Metodologia de Análise de Risco para a Mitigação da Responsabilidade Objetiva Diante da Lei Anticorrupção (12.846/2013) em Face de Negócios Públicos

Logo, um programa de compliance robusto deve ser adaptado e personalizado levando em conta a realidade da empresa, o nível de segurança das informações, o nível de autonomia dos funcionários, o grau de controle efetivamente praticado sobre os atos dos funcionários em diferentes níveis hierárquicos, bem como a tolerância com o não seguimento das normas internas praticadas na organização, devendo garantir o constante aprimoramento e adaptação do referido programa, visando garantir sua efetividade.

O decreto Lei que regulamentou os programas de compliance traz critérios a serem considerados pelas autoridades administrativas, destacando a importância do comprometimento da alta direção, da criação de padrões de conduta, código de ética, políticas de integridade, treinamentos periódicos, canais de denúncia e diligências contábeis e pré-contratuais, bem como relatórios e controles internos.

A análise de risco é fundamental e o primeiro passo para inaugurar um programa robusto de compliance. Também conhecida como "risk assessment", esta etapa leva em conta as circunstâncias individuais da companhia, pontualmente os riscos prováveis relacionados às atividades que a mesma desenvolve. $\mathrm{O}$ mapeamento dos riscos é alocado em uma matriz de riscos.

Sabidamente existem determinados países e atividades que estão mais expostos a riscos de corrupção, e estes fatores devem ser levados em consideração no processo de mapeamento. Os rankings internacionais de percepção da corrupção promovidos pelo World Bank Institute dão indícios das localizações geográficas em que haveria uma "maior demanda corruptiva".

Alguns setores também se encontram particularmente mais expostos à corrupção, em face da exigência de "pagamentos de facilitação" ou da necessidade contínua de contato com autoridades públicas. Outrossim, o volume de contratos com intermediários ou terceirizados pode aumentar o risco de exposição da empresa à corrupção.

\section{QUANTIFICANDO OS RISCOS: RISCOS INERENTES E RISCOS RESIDUAIS}

De acordo com Fernandes (2015, p. 16) risco é o potencial de perda existente em determinada ação (ou ausência de determinada ação), sendo incerto a sua ocorrência e que ocorre quando uma ameaça encontra uma vulnerabilidade ou um conjunto de vulnerabilidades nos sistemas de proteção, permitindo a concretização do risco. ${ }^{2}$

De acordo com o autor, o conceito de risco não deve ser confundido com o de meaça evulnerabilidade. Enquanto a ameaça está intimamente ligada ao vetor que a conduz, 
o risco está intimamente ligado a sua concretização. Já a vulnerabilidade é uma deficiência nos processo, nos sistemas, ou nos recursos humanos empregados que permite a concretização dos riscos a que a organização está exposta.

$\mathrm{Na}$ metodologia de análise de risco que se pretende aplicar aos riscos de corrupção, o diálogo com as diversas áreas da empresa é fundamental para identificação de riscos potenciais.

De maneira genérica, alguns pontos devem ser observados: os setores do mercado em que atua no Brasil e no exterior; estrutura organizacional (hierarquia interna, processo decisório e as principais competências de conselhos, diretorias, departamentos ou setores); quantitativo de funcionários e demais colaboradores; nível de interação com a administração pública, considerando-se principalmente a relevância de processos de obtenção de autorizações, licenças e permissões governamentais em suas atividades, o quantitativo e os valores de contratos celebrados com entidades e órgãos públicos, a frequência e a relevância da utilização de terceiros nas interações com o setor público; participações societárias que envolvam a pessoa jurídica na condição de controladora, controlada, coligada ou consorciada.

A gestão de riscos proposta pela metodologia do Pacto Global compreende três passos principais:

(i) identificação de situações de risco, mapeamento de situações ou fatores que possam facilitar, camuflar ou contribuir para prática de atos lesivos contra a administração pública, nacional ou estrangeira.

(ii) Criação de políticas para mitigar os riscos com base nesse levantamento, desenvolver políticas com o objetivo de aumentar o controle sobre as situações de risco e diminuir as chances de ocorrência de atos lesivos.

(iii) Análise periódica de riscos e atualização das políticas, mudanças no cenário de risco podem trazer a necessidade de adaptações e, até mesmo, reformulações nas políticas e controles estabelecidos pela empresa.

No que tange aos padrões escritos, é indispensável que estes contemplem políticas específicas pensadas na realidade da empresa, e forneçam orientações precisas que atendam as demandas tanto dos colaboradores internos quanto de terceiros que se relacionem com a empresa.

O cenário e o ambiente externo em que a empresa se insere compõem os chamados fatores de risco, que são por definição: 
razões pelas quais a corrupção ocorre em uma empresa com base no seu ambiente, incluindo a natureza das suas operações e localizações" (Guia de Avaliação de Risco de Corrupção, 2015, p. 24).

Uma vez identificados por meio de entrevistas, coletas de dados e pesquisa documental os riscos de corrupção a que a empresa est sujeita em todas as suas áreas, e documentá-los, passa-se a análise específica em cada área. Por exemplo, subornos e propinas nos departamentos comerciais, esquemas de superfaturamento, pagamentos de liberação alfandegária no setor de importação.

Após identificados e documentados, os riscos de corrupção levantados deverão ser classificados levando em consideração a probabilidade de sua ocorrência (ignorando neste primeiro momento a existência de controles para mitigá-los).

$\mathrm{Na}$ sequência, avalia-se a magnitude do impacto potencial de cada esquema de corrupção em particular, levando em consideração os danos financeiros, legais, regulatórios, operacionais e reputacionais. Aqui é o momento em que as sanções previstas na Lei 12.846/13 devem ser cuidadosamente levadas em consideração, em especial no que tange ao valor da multa (que poderá atingir até $20 \%$ do faturamento bruto) o custo de oportunidade das restrições legais e regulatórias da empresa para operar e expandir, contratar com órgãos públicos ou conseguir empréstimos de bancos estatais.

Para a classificação qualitativa dos riscos, propõe-se uma escala de 1 a 5, para avaliar o impacto doo risco (sua gravidade em termos de consequências provocadas). Para avaliação da probabilidade considera-se se a frequência em que o evento poderia ocorrer é muita alta, alta, média, baixa ou muito baixa.

Ao combinar as avaliações de impacto e probabilidade para cada esquema de corrupção, o resultado nos mostra o risco inerente.

“O risco inerente representa o nível de risco geral de cada esquema, sem considerar os controles existentes. É nessas áreas em que controles mitigantes serão provavelmente mais importante na mitigação de esquemas de corrupção." (Guia de Avaliação de Risco de Corrupção,

2015, p. 31)

Após o cálculo do risco inerente, analisa-se a capacidade de proteção, verificando se há algum controle, ferramenta ou estratégia adotada pela companhia com o condão de minimizar o risco avaliado. 
$\mathrm{Na}$ documentação dos seus controles, uma empresa deve diferenciar entre controles específicos de negócio e controles anticorrupção gerais (nível da empresa). Identificar controles no nível do processo de negócio e não apenas no nível de risco é importante, já que processos diferentes tendem a ter controles de mitigação diferentes. (Guia de Avaliação de Risco de Corrupção, 2015, p. 35)

Na sequência, deve ocorrer a análise do referido controle de mitigação do risco de corrupção, e apuração de sua efetividade. Por exemplo, diante de um risco de pagamento de propina alfandegária, qual seria a efetividade de um mecanismo de proteção como um canal de denúncias ou um treinamento dos funcionários? A capacidade de proteção ao risco, também deve estar disposta numa escala quantitativa de 1 a 5 , sendo 1 , uma capacidade de proteção muito eficiente e

5 uma capacidade de proteção ineficiente.

"Risco residual é a medida de risco remanescente depois de se considerar o impacto dos controles na redução de risco. O risco residual é um fator do risco inerente e da classificação de controle." (Guia de Avaliação de Risco de Corrupção, 2015, p.42)

Esta classificação quantitativa é importante, pois determinará o risco residual e o grau de atenção que deve ser dispensado pela administração perante os riscos com maior exposição.

O risco residual pode ser calculado como risco inerente somado a classificação do controle ou risco inerente multiplicado pela classificação o controle. As faixas de pontuação precisarão ser atribuídas para determinar se o risco residual é alto, médio ou baixo e a partir daí, determinar planos de ação específicos para cada um deles.

\footnotetext{
“As classificações de risco residual fornecem à administração uma avaliação de onde pode estar sua maior exposição aos riscos de corrupção. Uma classificação de alto risco residual significaria que um risco de corrupção inerente alto não é substancialmente mitigado por controles, deixando um risco residual que pode afetar seriamente a empresa. Risco residual médio significaria que o esquema de corrupção é inerentemente de alto risco, e parcialmente mitigado por controles ou inerentemente médio risco e não substancialmente ou de forma alguma mitigado por controles. Baixo risco residual significaria que o esquema de corrupção é inerentemente de risco classificado como baixo, ou é substancialmente mitigado por controles." (Guia de Avaliação de Risco de Corrupção, 2015, p.43)
}

O plano de ação deve estar intimamente ligado com a tolerância de risco definida pela empresa. Quando o risco residual extrapolar os parâmetros de tolerância estipulados faz-se necessária uma ação para reduzir o risco até que ele esteja dentro do limite de tolerância desejável. 
Uma vez identificados, classificados os riscos inerentes, avaliadas as ferramentas de controle obtendo-se os riscos residuais e executados os devidos planos de ação, é preciso que haja um monitoramento contínuo deste processo de compliance.

Aqui se propõe a existência de indicadores de performance objetivando a melhoria contínua dos controles de mitigação de riscos, e a redução progressiva da tolerância ao risco pela empresa.

\section{CONCLUSÃO}

Embora a lei anticorrupção tenha um amplo alcance no que tange aos destinatários, o artigo objetivou tratar dos negócios jurídicos celebrados entre empresas brasileiras com a administração pública nacional.

A responsabilização objetiva das pessoas jurídicas por infrações cometidas nos negócios jurídicos celebrados com a Administração Pública é uma inovação importante no ordenamento jurídico brasileiro. As sanções nas esferas administrativas e civil podem provocar severos impactos nas empresas que forem condenadas por praticar as condutas descritas no artigo quinto da Lei Anticorrupção.

A importância da Lei 12.846/13 entretanto, não restringe-se ao seu aspecto repressivo. Ao dispor que os programas de integridade, auditoria e incentivo à denúncia de irregularidades e a aplicação efetiva de códigos de ética e de conduta no âmbito da pessoa jurídica, serão levados em consideração na aplicação das sanções, reconhece-se notadamente que as empresas possuem o compromisso ético de serem agentes ativos no combate a corrupção.

Ao promover a adoção de Programas de Integridade e conformidade (compliance) de modo a mitigar a responsabilidade objetiva, a lei prestigia a formação de uma ética empresarial.

A implementação de programas de compliance nas empresas deve inaugurar uma mudança de cultura organizacional, Um dos caminhos para promover essa mudança na cultura Torganizacional é por meio da gestão por valores, ao elevar transparência, integridade, à categoria de valores estratégicos para a consecução dos objetivos da companhia reduz-se os riscos de corrupção tanto em âmbito interno, como nos negócios jurídicos celebrados com a administração pública.

O Decreto 8.420/15 aduz que o "programa de integridade deve ser estruturado, aplicado e atualizado de acordo com as características e riscos atuais das atividades de cada 
pessoa jurídica, a qual por sua vez deve garantir o constante aprimoramento e adaptação do referido programa, visando garantir sua efetividade.".

Desta forma, a metodologia de análise de risco apresentada pelo Pacto Global é uma importante ferramenta para a criação de um programa robusto e eficaz de compliance.

A identificação dos riscos, permite a empresa um diagnóstico das áreas mais sensíveis da empresa, fazendo uma análise tanto das ameaças externas quanto dos fatores internos que facilitem, camuflem ou contribuam para prática de atos lesivos contra a administração pública, nacional ou estrangeira.

Os riscos devem ser quantificados em face do impacto que venham a provocar caso se concretizem, e da probabilidade de que efetivamente ocorram, encontrando assim um coeficiente chamado "risco inerente".

Em seguida, as formas de controle (compliance) e as ferramentas de mitigação dos riscos de corrupção serão analisadas tomando por base a capacidade de proteção de um controle em face de um risco existente. (v.g canal de denúncia, treinamentos, registros contábeis, checklists).

Isto feito, encontrar-se-á matematicamente o chamado risco residual, que orientará a criação de planos de ação e políticas específicas quando ultrapassarem os parâmetros fixados pela empresa como aceitáveis.

As análises periódicas de riscos, e os planos de ação montados para mitigar os que forem mais sensíveis, deverão sempre ser documentadas e servirão como base probatória em eventuais processos administrativos movidos em face da empresa.

A metodologia de análise contínua de riscos apresentada no trabalho, baseada em critério quantitativos e qualitativos, é atualmente a forma mais eficaz de evitar infrações em face da administração pública e mitigar a responsabilidade objetiva da empresa. Isto porquê, além do embasamento probatório que a adoção da metodologia de análise de risco produz, fica certamente mais fácil para a empresa realizar investigações internas e apurar os responsáveis por eventuais infrações, afastando a responsabilidade administrativa da pessoa jurídica, e responsabilizando efetivamente os colaboradores que agiram com dolo.

Assim, representa importante passo para elevar o nível de transparência e integridade nos negócios jurídicos realizados pelos entes público e privados, tendo a Lei 12.846/13 papel importante no estímulo a adoção de programas de integridade e consequentemente na redução dos riscos de corrupção em face da administração pública. 


\section{REFERÊNCIAS BIBLIOGRÁFICAS:}

BRASIL, Decreto 8420 de 18 De Março de 2015. Disponível em: http://presrepublica.jusbrasil.com.br/legislacao/175006740/decreto-8420-15. Acesso em 23 de março de 2015.

BRASIL, Lei 12.846, de $1^{\circ}$ de agosto de 2013. Disponível em:

http://www.planalto.gov.br/ccivil_03/_ato2011-2014/2013/lei/112846.htm Acesso em 23 de março de 2015.

BACIGALUPO, Enrique. Compliance y derecho penal. Navarra: Aranzadi, 2011.

CARVALHOSA, Modesto. Considerações sobre a Lei anticorrupção das pessoas jurídicas:

Lei n. 12.846 de 2013. São Paulo: Revista dos Tribunais, 2015.

DOLAN, Simon L. GARCIA, Salvador. Gestão por Valores. Porto: Biorumo, 2006.

FERNANDES, Nelson Ricardo. Análise de Risco Parametrizada: Manual Prático do

Planejamento e Gestão de Riscos. Editora Clube do Autor, 2015.

MARZA, Domingo Garcia. PIZZI, Jovino (trad.) Do Diálogo à confiança na empresa. Editora Unisinos: 2004.

MEIRELLES, Hely Lopes. Direito Administrativo Brasileiro. São Paulo: Malheiros, 2003.

MELLO, Celso Antonio Bandeira. Curso de Direito Administrativo. 32. ed. São Paulo:

Malheiros Editores, 2015.

SCHEIN, Edgar H. Cultura Organizacional e Liderança. Editora Atlas: São Paulo: 2009

CGU, Programa de Integridade: Diretrizes para Empresas Privadas. Equipe Técnica:Diretoria de Promoção da Integridade, Acordos e Cooperação Internacional. Brasília, setembro de 2015.

The Global Compact. Guia de Avaliação de Risco de Corrupção. Copyright United Nations Global Compact Office. 